\title{
Mining pollution and sedimentation, release flux of heavy metal at sediment-water interface in Wujiangdu Reservoir
}

\author{
QINGQING Sun ${ }^{1, *}$, Siliang Li ${ }^{1}$, KEQIANG PENG ${ }^{2}$ \\ ${ }^{1}$ Institute of Surface-Earth System Science, Tianjin \\ University, Tianjin 30072, China ${ }^{*}$ correspondent: \\ sunqingqing17@tju.edu.cn) \\ ${ }^{2}$ State Key Laboratory of Ore Deposit Geochemistry, Institute \\ of Geochemistry, Chinese Academy of Sciences, Guiyang \\ 550081, China (pengkeqiang@mail.gyig.ac.cn)
}

China now has 98,822 DAMS, including 51,643 on the Yangtze River. Annual sediment discharge at Datong is $77.4 \%$ lower than multi-year average. At Wulong of Wujiang River, a upstream tributary of the Yangtze River, it decreased by $88.9 \%$. Wujiangdu Reservoir $\left(\mathrm{E} 106.5^{\circ}, \mathrm{N} 27.3^{\circ}\right)$, one of step reservoirs in Wujiang River, was built in 1979, undertakes power generation, flood control functions. Longterm mine pollution, cage aquaculture, and dams formed unique coupling geochemical cycles between heavy metals and organic matter. Mean sedimentation rate is $0.48 \mathrm{~cm} / \mathrm{a}$, and average deposition rate of sediments is $0.156 \mathrm{~g} /\left(\mathrm{cm}^{2} \cdot \mathrm{a}\right)$. Due to phosphate ore pollution, TP in Yangshui River, a tributary of the reservoir, is up to $87 \mathrm{mg} / \mathrm{L}$. Cage culture and mine pollutions have been banned in the last two years. The contents of TOC and TN in the sediment profiles indicated sedimentation-degradation-accumulation model in diagenetic degradation of organic matter. Heavy metals, associated with phosphate ore, in sediments may be re-released into the overlying water through biological or physicochemical processes, resulting in continuous migration and exchange, which easily migrate and transform into the food chain and cause ecological risks. V(V), $\mathrm{Cr}(\mathrm{VI}), \mathrm{As}(\mathrm{V}), \mathrm{Se}(\mathrm{IV}), \mathrm{Mo}(\mathrm{VI})$, $\mathrm{Sb}(\mathrm{V}), \mathrm{W}(\mathrm{VI}), \mathrm{Pb}(\mathrm{II}), \mathrm{Mn}(\mathrm{II}), \mathrm{Co}(\mathrm{II}), \mathrm{Ni}$ (II), $\mathrm{Cu}(\mathrm{II}), \mathrm{Zn}(\mathrm{II})$, $\mathrm{Cd}(\mathrm{II}), \mathrm{P}(\mathrm{V})$, and $\mathrm{Fe}(\mathrm{II})$ were synchronously monitored by ZrO-Chelex diffusive gradient in thin films technique, molybdenum-antimony anti-spectrophotometric method, inductively coupled plasma optical emission spectrometer and mass spectrometry. The mean fluxes were respectively $(1.96$ $\times 10^{-5}, 1.34 \times 10^{-4}, 5.57 \times 10^{-4}, 1.12 \times 10^{-5}, 7.03 \times 10^{-4}, 1.15 \times 10^{-4}$, $2.05 \times 10^{-5}, 8.81 \times 10^{-5}, 0.074,4.48 \times 10^{-5}, 1.74 \times 10^{-4}, 9.1 \times 10^{-5}$, $1.22 \times 10^{-3}, 2.05 \times 10^{-4}, 0.100$, and 0.159$) \mathrm{ng} /\left(\mathrm{cm}^{2} \cdot \mathrm{s}\right)$. The forms of heavy metals in sediments were mainly composed of Exchangeable State and Bound State to Fe-Mn Oxides. With the increase of the service time of the reservoirs, sedimentation reduces the storage capacity, it is necessary to control exogenous input, endogenous release, and formulate eco-friendly sediments discharge management plan. 